\title{
Dos pinturas inéditas de José García Ramos o el ideal pictórico andaluz
}

\author{
Álvaro Cabezas García \\ Universidad de Sevilla \\ alvarocabezasgarcia@gmail.com
}

En un domicilio particular de Sevilla se conservan dos lienzos firmados por José García Ramos (Sevilla, 1852-1912), desconocidos hasta ahora por la historiografía. Este hecho resulta ciertamente sorprendente ya que se trata de uno de los pintores e ilustradores hispalenses de mayor importancia en el contexto del tránsito de la pintura decimonónica a la propia de la centuria pasada y, consecuentemente, ha sido estudiado en varias ocasiones ${ }^{1}$.

Una de las pinturas inéditas podría recibir el título de Muchacha con guitarra [1] (óleo sobre lienzo, 65 x 88 cm), firmada en el ángulo inferior izquierdo, concretamente sobre la tapa del referido instrumento, como «J. García y Ramos». La otra podría llamarse Muchacha con abanico [2] (óleo sobre lienzo, 109 x 69 cm), y, asimismo, está rubricada por su autor de la misma manera, pero en esta ocasión, en el ángulo inferior derecho, sobre el fondo negro.

Esta modalidad de firma [3] es la utilizada por José García Ramos desde el año 1896 en adelante, con la práctica intención de diferenciar su producción de la de su hermano menor Juan (Sevilla, 1856-1915) (Izquierdo, 2012: 15). Este detalle, por consiguiente, ayuda a datar la realización de ambas pinturas en el periodo de mayor esplendor y crédito de la obra de García Ramos: los últimos años del siglo XIX, momento en que abandona las composiciones conformadas por varios personajes típicos o de raigambre andaluza -situados en la mayoría de ocasiones en ámbitos urbanos o campestres-, y casi siempre asociados con las celebraciones o las costumbres, para escoger tan solo uno, preferentemente femenino, con el que poder ocupar toda la composición -ahora sobre fondo oscuro-, sin excluir uno o varios elementos evocadores de los hábitos y tradiciones idiosincráticos del costumbrismo: mantones de Manila, zambombas, panderetas, sillas de enea o, como ocurre en los casos aquí expuestos, guitarras o abanicos.

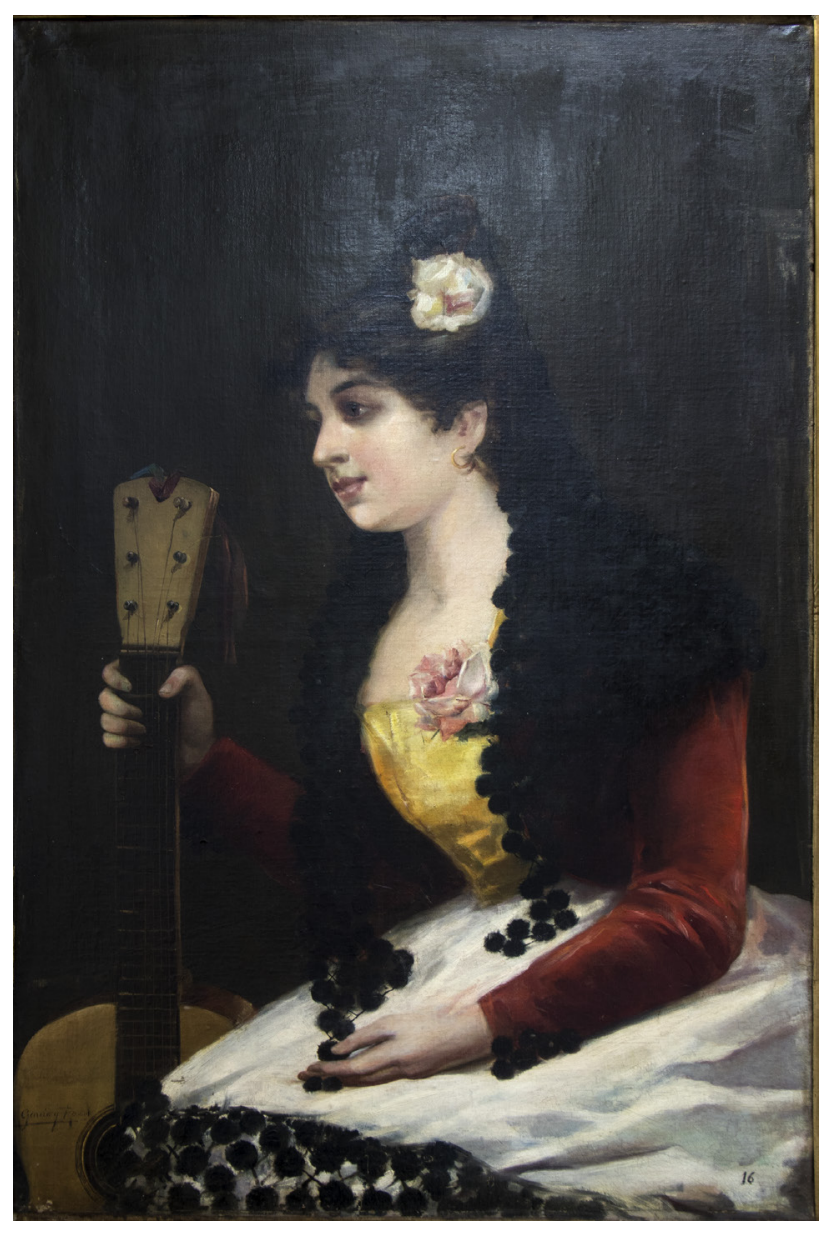

1. Sevilla. Colección particular. Muchacha con guitarra. José García Ramos. c. 1896

La iconografía de las mujeres de las pinturas presentadas en estas páginas por primera vez se completa con una serie de detalles indumentarios tratados de manera exquisita y minuciosa por el artista como, en la primera de ellas, la madroñera negra que, sujeta por medio de una peineta, cae 


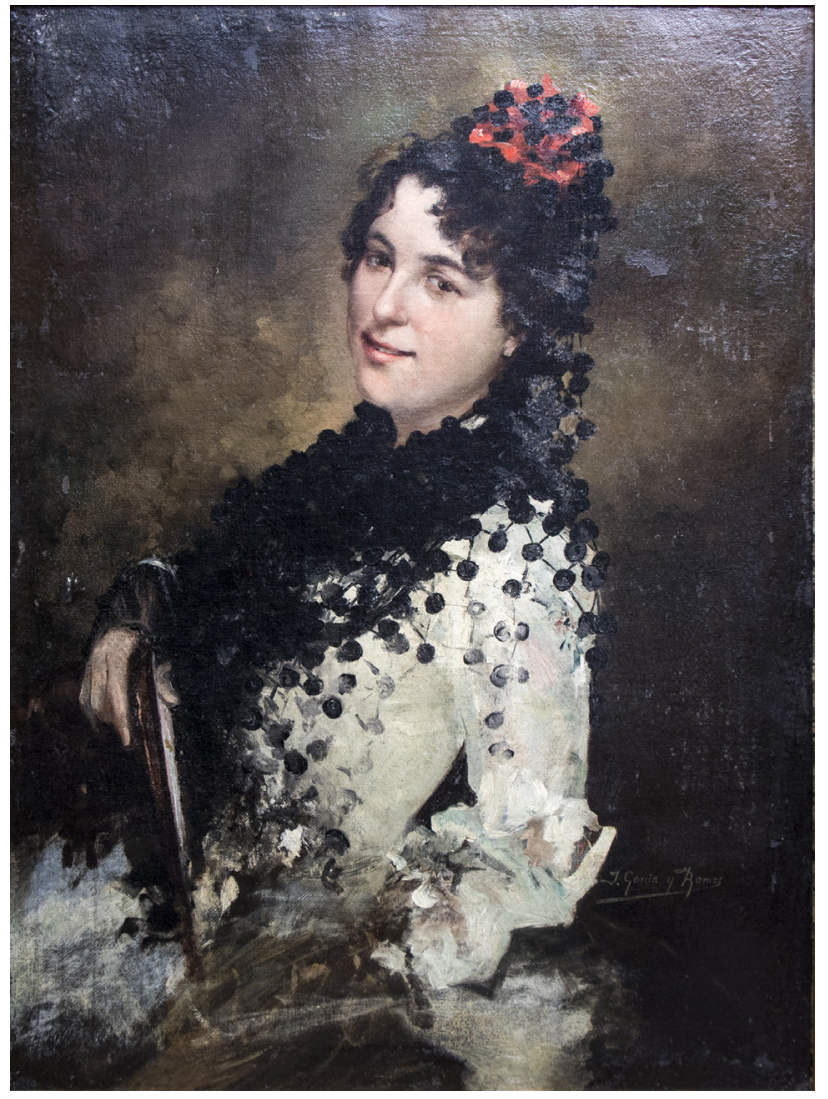

2. Sevilla. Colección particular. Muchacha con abanico. José García Ramos. C. 1896

sobre los hombros, y es contrastada por sendos toques de color gracias a las lozanas rosas que lleva colocadas a un lado de la cabeza y en el busto. Después está la gama de colores: amarillo del corpiño, granates las mangas y blanca la falda adornada de madroños en el vuelo. En la segunda, la oscura madroñera está dispuesta de una manera similar sobre la cabeza de la fémina, vuelta hacia el espectador: sobre peineta, cuyo engarce está intachablemente disimulado por la colocación de una flor roja, cayendo graciosamente por los hombros y el pecho, ahora cubiertos por un vestido blanco. Ambas figuras se muestran sentadas en un medio completamente descontextualizado: no se diferencia el soporte, como sí ocurre con el castizo asiento y la mesa de la análoga pintura del autor Mujer con pandereta (Sevilla, colección particular, c.1896)-, con el fondo de árboles de Mujer con guitarra (Sevilla, colección particular, c.1896) o con el del coso maestrante de A la corrida de toros (Cano, 2012a: 30). En ese sentido, la pintura con la que más podría relacionarse es con la solitaria Muchacha con abanico firmada y subastada en Christie's Ámsterdam (27-11-2012).

Todo lo anterior indica la existencia de una etapa de transición en la trayectoria de García Ramos, entre la de su insistente presencia en las ilustraciones de publicaciones de enorme divulgación ${ }^{2}$-en la que llevaría a su máxima cota de calidad el género costumbrista- (Calvo, 1981: 63-75; Cano, 2012a: 25-31), y la última de su vida, caracterizada por un cierto decaimiento anímico y bien diferenciada por la recurrente utilización de tonos pardos (1900-1912) (Valdivieso, 1981: 118). Ahora refleja un latente ensimismamiento y una sobresaliente técnica pictórica, tal como si el artista solo quisiera recrearse en la plasmación de los modelos como adecuada excusa del desarrollo, per se, de su pintura. Justamente, cuando acometió la ejecución de estos lienzos, era el pintor más preeminente de su época en Sevilla -posición que compartió con gusto con su admirado José Jiménez Aranda (Sevilla, 1837-1903)-, algo que prueba su nombramiento como académico numerario de la Real de Bellas Ar-

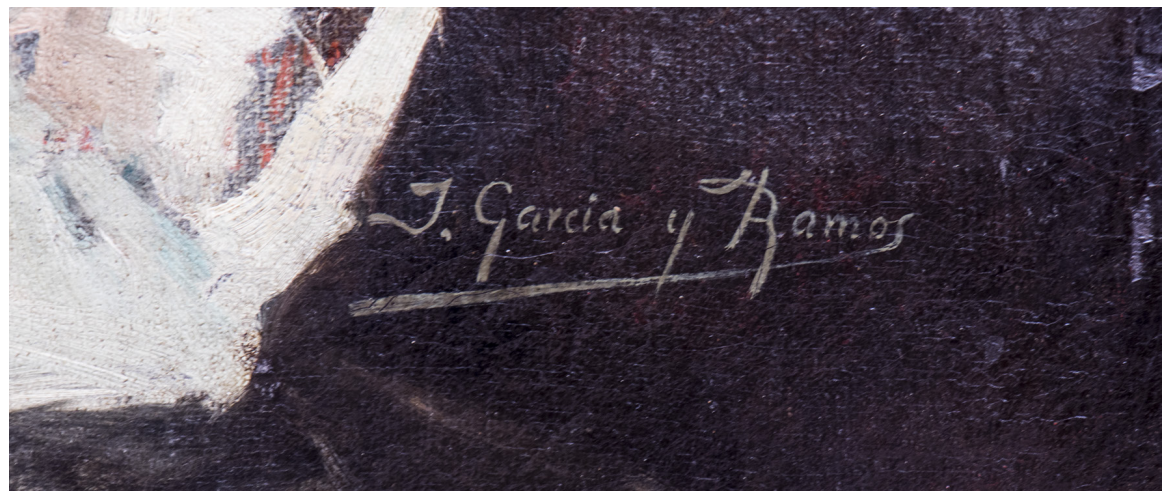

3. Sevilla. Colección particular. Muchacha con abanico. José García Ramos. c.1896. Detalle de la firma 
tes de Santa Isabel de Hungría de Sevilla en 1893 (Muro, 1961: 173), después de haberse atraído la atención de la oficialidad en el seno de la autogestionaria, artísticamente hablando, Academia Libre de Bellas Artes de Sevilla desde su fundación en $1872^{3}$.

Efectivamente, en la última década de la centuria decimonónica, se dieron las circunstancias favorables para esta posición en la cúspide de la Escuela sevillana de pintura al coincidir cronológicamente con la época otoñal de Eduardo Cano de la Peña (Madrid, 1823-Sevilla, 1897), quien personificó la oficialidad hispalense en grado sumo durante los veinte años anteriores (Pérez, 1979: 39). Cuando García Ramos se estableció en Sevilla al declinar el siglo -después de probar suerte con la pintura de casacón en Roma (1872-1875, 1877-1880), París (1881) y otros lugares de España, casi siempre siguiendo a Jiménez Aranda (Izquierdo, 2012: 12 y 13)-, su consagración artística vino como consecuencia de la alternativa que planteó con la práctica de la pintura costumbrista, una tipología que deshabilitaba en el escenario cotidiano de la ciudad del Guadalquivir las dos grandes tendencias internacionales propias de las décadas anteriores: la pintura de Historia de Eduardo Cano (Fernández, 1985) y la de casacón de Jiménez Aranda, renombrada recientemente como pintura neorrococó (Cabezas, 2018: 1.091). La invitación de García Ramos era un nuevo costumbrismo, alejado del romántico y murillista que, entre 1830 y 1870, aproximadamente, desplegaron los Domínguez Bécquer, los Cabral Bejarano o los Hispaletos ${ }^{4}$. El suyo era, por contra, un costumbrismo realista, que no reproducía la imagen de la Sevilla creada (Colón, 1991) por los viajeros foráneos -y que solo existía en su literatura de viajes (Alberich, 2000) y en la pin- tura que encargaban ex profeso (Plaza, 2019: 35-52)-, sino la cotidiana y real que, con gracia popular, aun se daba con frecuencia y naturalidad en determinados enclaves urbanos. Esta nueva variante del género ya no era promovida y consumida solo por los turistas como objetos de souvenir, sino también, y cada vez más, por la incipiente élite social que abonaba en el pensamiento político común cada una de las peculiaridades regionales como mecanismos necesarios a la hora de la toma de decisiones públicas.

De esta manera, las pinturas aquí presentadas deben entenderse como figuraciones regionalistas: ventanas directas para la contemplación de una mujer solitaria que evoca, más que demuestra, su sentido de pertenencia a una comunidad, gracias no solo a los atributos característicos -abanico, atuendo, guitarra- atenuados en su representación y uso, sino en el decisivo carácter que deja entrever un semblante identificable, casi racialmente, como propiamente sevillano, y por ende, andaluz y español ${ }^{5}$. No es de extrañar, por tanto, que se le encargara a García Ramos pintar el cartel de las fiestas de primavera que, anualmente, convocaba por concurso el Ayuntamiento hispalense -y que realizó en tres ocasiones-, constituyendo un modelo codificado de representación iconográfica sevillana, ampliamente desarrollado desde entonces y hasta fechas muy recientes (Sevilla, 1993). Algunos de sus discípulos ensayaron mantener viva la llama del maestro ${ }^{6}$, pero la rigurosa cesura que marcó la Guerra Civil con la pintura precedente abandonó en la reminiscencia ${ }^{7}$, más que en el olvido, el notable avance estético procurado por José García Ramos en su punto álgido como pintor con este tipo de representaciones femeninas.

\section{Notas}

1 El primero que se ocupó de su estudio fue Ossorio, 1883-1884: 279. Le siguió Cascales, 1912; 1929: 14-15. Algún discípulo afogó su aprecio, como Grosso, 1973. Por otro lado, los estudios de carácter general son los de Cardiel, 1960: 21-116. Iglesias, 1976: 60-61. Valdivieso, 1981: 116-118, 126 y 133. 1986: 425-429. Rodríguez, 2000: 562-566. Los reunidos en las exposiciones que se le dedicaron son Sevilla, 1997; Sevilla, 2012a y Sevilla, 2012b. Algunos otros se centraron en su faceta de ilustrador de medios escritos: Cabalga, 2018: 740-748. Como dibujante, véase Puente, 1956: $248-262$ y Pardo, $1973: 361-362$.

2 Me refiero tanto a las publicaciones periódicas La llustración Española y Americana, La llustración Artística, Hispania o Blanco y Negro, desde 1891 -de cuya importancia para la estética de la época dio cuenta Camón, 1955: 17-19-, como a las personales de Salvador Rueda: Granada y Sevilla, bajo relieves, 1890, Benito Mas y Prat: La tierra de María Santísima, Cuadros flamencos, 1891 o Manuel Héctor Abreu: Matar por matar, 1908; o las colectivas de Luis Montoto: Historia de muchos Juanes, 1898, y de la Academia Sevillana de Buenas Letras: Rinconete y Cortadillo, 1905, por citar solo los más importantes proyectos editoriales a los que contribuyó con su pincel García Ramos, como comentó Muñoz, 2012: 22-23.

3 Pérez, 1998: 280, aclara que se vinculó a esta institución, sobre todo, cuando regresó definitivamente a Sevilla en 1885 , llegando a presidirla en 1886.

4 El mejor estudio es el de Reina, 1979. Sobre el murillismo en la pintura sevillana del siglo XIX, véase Lleó, 2017: 91-99; Valdivieso, 2018 y Cabezas, 2019 : 31-47.

5 De hecho, su pintura Mujer con mantón y abanico (Sevilla, Museo de Artes y Costumbres Populares, c. 1900), fue expuesta en el Palacio de Cristal del Retiro por el Círculo de Bellas Artes bajo el título Un tipo de Sevilla como señala Cano, 2012b: 154-155. 
6 La más atractiva derivación de esta opción pictórica de García Ramos fue la representación de mujeres con «sonrisa-elixir» de Grosso. Hurtado, $1994:$ 17-27.

7 Pese al vaticinio que había expresado años antes su compañero de estudios, el pintor Mattoni, 1920: 143, quien afirmó que «su obra no pasará jamás».

\section{Bibliografía}

ALBERICH, José María (2000), Del Támesis al Guadalquivir. Antología de viajeros ingleses en la Sevilla del siglo XIX, Universidad de Sevilla, Sevilla.

CABALGA SALGUEIRO, Diego (2018), «José García Ramos y sus ilustraciones cofradieras: el costumbrismo sevillano y sus representaciones artísticas", Boletín de las cofradías de Sevilla, n. ${ }^{\circ} 718$, pp. 740-748.

CABEZAS GARCÍA, Álvaro (2018), «La pintura de casacones en España y América: una visión retrospectiva e idealizada del siglo XVIIl», en PÉREZ SAMPER, M. ${ }^{a}$ Ángeles y BETRÁN MOYA, José Luis (eds.), Nuevas perspectivas de investigación en Historia Moderna: Economía, Sociedad, Política y Cultura en el Mundo Hispánico, Fundación Española de Historia Moderna, Madrid, pp. 1.088-1.101.

- (2019), "En la senda de Murillo», en ROMÁN VILLALÓN, Álvaro (coord.), En la senda de Murillo: Tovar y la Divina Pastora. Cat. exp. Diputación de Huelva, Huelva, pp. 31-47.

CALVO SERRALLER, Francisco (1981), «La pintura costumbrista española», en MUÑOZ ROJAS, José Antonio, ALBERICH, José y BRAVO VILLASANTE, Carmen (dirs.), La imagen romántica de España. Cat. exp., Madrid, 1981, pp. 63-75.

CANO RIVERO, Ignacio (2012a), "García Ramos, pintor costumbrista con Sevilla de fondo», en García Ramos en la pintura sevillana. Cat. exp., Consejería de Cultura, Sevilla, pp. 25-31.

- (2012b), «José García Ramos, Sevilla, 1852-1912. 61. Mujer con mantón y abanico (Tipo sevillano), hacia 1900», en García Ramos en la pintura sevillana. Cat. exp., Consejería de Cultura, Sevilla, pp. 154-155.

CAMÓN AZNAR, José (1955), «Blanco y Negro y ABC», ABC de Madrid, 28-12-1955, pp. 17-19.

CARDIEL MARTíNEZ, María del Pilar (1960), "García Ramos. Pincel sevillano», Archivo hispalense, n. 99, pp. 21-116.

CASCALES Y MUÑOZ, José (1912), “José García y Ramos 1852-1912», en La llustración Española y Americana, 15-4-1912.

- (1929), Las Bellas Artes plásticas en Sevilla. Colegio de Huérfanos de María Cristina, Toledo.

COLÓN PERALES, Carlos (1991), Lacrimae. La Sevilla imaginaria, Ediciones Alfar, Sevilla.

FERNÁNDEZ LÓPEZ, José (1985), La pintura de Historia en Sevilla en el siglo XIX, Diputación de Sevilla, Sevilla.

GROSSO, Alfonso (1973), «José García Ramos y Gonzalo Bilbao», en Homenaje a José García Ramos y Gonzalo Bilbao, Galería Loring, Madrid. HURTADO MARJALIZO, María Eugenia (1994), «Grosso, la última tipificación del realismo sevillano», en Alfonso Grosso. Catálogo de la exposición conmemorativa del centenario de su nacimiento. Cat. exp., Consejería de Cultura, Sevilla, pp. 17-27.

IGLESIAS RUBIO, José María (1976), «García Ramos», Bellas Artes, n. 53, pp. 60-61.

IZQUIERDO MORENO, Rocío (2012), «José García Ramos. Apunte biográfico», en García Ramos en la pintura sevillana. Cat. exp., Consejería de Cultura, Sevilla, pp. 12-17.

LLEÓ CAÑAL, Vicente (2017), «Murillo en la Sevilla del siglo XIX», en NAVARRETE PRIETO, Benito (dir. cient.), Murillo y su estela en Sevilla. Cat. exp., Ayuntamiento de Sevilla, Sevilla, pp. 91-99.

MATTONI, Virgilio (1920), «Sevilla en sus pintores», en MONTOTO RAUSTENSTRAUCH, Santiago (dir.), Quien no vio Sevilla, Ayuntamiento de Sevilla, Sevilla, pp. 101-114.

MUÑOZ RUBIO, María del Valme (2012), «Apuntes en el centenario de la muerte de José García Ramos», en García Ramos en la pintura sevillana. Cat. exp., Consejería de Cultura, Sevilla, pp. 18-24.

MURO OREJÓN, Antonio (1961), Apuntes para la historia de la Academia de Bellas Artes de Sevilla, Imprenta Provincial, Sevilla.

OSSORIO Y BERNARD, Manuel (1883-1884), Galería biográfica de artistas españoles del siglo XIX, Imprenta a cargo de Ramón Moreno, Madrid.

PARDO CANALíS, Enrique (1973), «Un dibujo de García Ramos», Goya, n. 114, 361 - 362.

PÉREZ CALERO, Gerardo (1979), El pintor Eduardo Cano de la Peña (1823-1897). Universidad de Sevilla, Sevilla. 
PÉREZ CALERO, Gerardo (1998), «La Academia Libre de Bellas Artes de Sevilla (1872-1888)», Laboratorio de Arte, n. ${ }^{\circ} 11$, pp. $275-300$.

PLAZA ORELLANA, Rocío (2019), «Gran Bretaña en Andalucía. Los viajes de los pintores británicos (1800-1830)», en MÉNDEZ RODRíGUEZ, Luis y PLAZA ORELLANA, Rocío (coords.), Andalucía, la construcción de una imagen artística, Universidad de Sevilla, Sevilla, pp. $35-52$.

PUENTE, Joaquín de la (1956), «Los dibujos de José García y Ramos en el Museo Nacional de Arte Moderno. Digresión, comentario y catálogo», Revista de Arte Español, pp. 248-262.

REINA PALAZÓN, Antonio (1979), La pintura costumbrista en Sevilla, 1830-1870, Universidad de Sevilla, Sevilla.

RODRÍGUEZ AGUILAR, Inmaculada Concepción (2000), Arte y cultura en la prensa: la pintura sevillana (1900-1936), Universidad de Sevilla, Sevilla.

Sevilla (1993), Un siglo de carteles de fiestas primaverales. Cat. exp., Caja San Fernando, Sevilla.

Sevilla (1997), José García Ramos. Un ilustrador de la vida sevillana. Cat. exp., Fundación El Monte, Sevilla.

Sevilla (2012a), García Ramos en la pintura sevillana. Cat. exp., Consejería de Cultura, Sevilla.

Sevilla (2012b), El pintor José García Ramos, 1852-1912. Cat. exp., Ateneo de Sevilla, Sevilla.

VALDIVIESO, Enrique (1981), Pintura sevillana del siglo XIX, Sevilla.

- (1986), Historia de la pintura sevillana, siglos XIII al XX, Guadalquivir Ediciones, Sevilla.

- (2018), La escuela de Murillo. Aportaciones al conocimiento de sus discípulos y seguidores, Universidad de Sevilla, Sevilla. 